\title{
A METHOD FOR ASSESSING SOIL VAPOR INTRUSION FROM PETROLEUM RELEASE SITES: MULTI-PHASE/MULTI-FRACTION PARTITIONING
}

\section{H. S. PARK}

Washington State Pollution Liability Insurance Agency, State of Washington, PO BOX 40930, Olympia, WA 98504-0930, USA

e-mail:hspark@olywa.net

\section{ABSTRACT}

A model and spreadsheet-based numeric approximation for computing risk-based soil cleanup level to be protective of petroleum-contaminated soil to an indoor air exposure pathway is presented. The algorithm incorporates traditional equilibrium partitioning equations ( 3 or 4-phase) for the conservation of mass and volume, as well as Raoult's law convention, and subsequent diffusive and convective transport mechanisms.

KEY WORDS: Raoult's Law, Soil Vapor, Equilibrium, Petroleum, Indoor Air, Partitioning

\section{INTRODUCTION}

A significant concern has been raised in the past several years regarding the risk to human health by the intrusion into and subsequent accumulation of contaminant vapors in buildings and other enclosed spaces. Complex mixtures of NAPL (Non-Aqueous Phase Liquid), such as petroleum hydrocarbons, contain components whose vapor pressure, water solubility, and partition coefficient range across several orders of magnitude. The relationship between subsurface concentrations and indoor air concentrations, arising from the migration of complex-petroleum-contaminated soil vapors into buildings, is presented based on a number of complex processes such as the equilibrium partitioning using TPH (Total Petroleum Hydrocarbons) surrogate approach and the attenuation. Individual TPH constituents are grouped into fractions in accordance with EC (Equivalent Carbon) number, with each fraction having no greater than an order of magnitude difference in the modeled environmental behavior of the constituents.

A database (Table 1) of contaminant-specific parameters, including solubility, S, organic-carbon partitioning coefficient, $K_{o c}$, molecular weight, MW, Henry's Law constant, $\mathrm{H}$, and inhalation reference concentration, $R f C$ is assembled for Benzene, Toluene and several different EC number ranges as proposed by the TPH Criteria Working Group (Gustafson et al., 1997). As shown in Table 2, comparisons are conducted for a wide range of TPH concentrations of seven representative fuels (WDOE, 1997). 
Table 1. Fate and Transport Characteristics and Associated Properties

\begin{tabular}{lcccccc}
\hline & $\boldsymbol{M} \boldsymbol{W}$ & $\boldsymbol{S}$ & $\boldsymbol{H}$ & $\boldsymbol{K}_{\boldsymbol{c}}$ & $\begin{array}{c}\text { Liquid } \\
\text { Density }\end{array}$ & $\boldsymbol{R} \boldsymbol{f} \boldsymbol{C}$ \\
\hline & $\mathrm{mg} / \mathrm{mol}$ & $\mathrm{mg} / \mathrm{L}$ & unitless & $\mathrm{L} / \mathrm{kg}$ & $\mathrm{mg} / \mathrm{L}$ & $\mathrm{mg} / \mathrm{kg}$-day \\
\hline Aliphatics & & & & & & \\
$\mathrm{EC}>5-6$ & $8.10 \mathrm{E}+04$ & $2.80 \mathrm{E}+01$ & $3.40 \mathrm{E}+01$ & $7.94 \mathrm{E}+02$ & $6.79 \mathrm{E}+05$ & 5.26 \\
$\mathrm{EC}>6-8$ & $1.00 \mathrm{E}+05$ & $4.20 \mathrm{E}+00$ & $5.10 \mathrm{E}+01$ & $3.98 \mathrm{E}+03$ & $7.26 \mathrm{E}+05$ & 5.26 \\
$\mathrm{EC}>8-10$ & $1.30 \mathrm{E}+05$ & $3.30 \mathrm{E}-01$ & $8.20 \mathrm{E}+01$ & $3.16 \mathrm{E}+04$ & $7.33 \mathrm{E}+05$ & 5.26 \\
$\mathrm{EC}>10-12$ & $1.60 \mathrm{E}+05$ & $2.60 \mathrm{E}-02$ & $1.30 \mathrm{E}+02$ & $2.51 \mathrm{E}+05$ & $7.60 \mathrm{E}+05$ & 0.286 \\
$\mathrm{EC}>12-16$ & $2.00 \mathrm{E}+05$ & $5.90 \mathrm{E}-04$ & $5.40 \mathrm{E}+02$ & $5.01 \mathrm{E}+06$ & $7.66 \mathrm{E}+05$ & 0.286 \\
$\mathrm{EC}>16-21$ & $2.70 \mathrm{E}+05$ & $1.00 \mathrm{E}-06$ & $6.40 \mathrm{E}+03$ & $1.00 \mathrm{E}+09$ & $7.80 \mathrm{E}+05$ & $\mathrm{NA}$ \\
Aromatics & & & & & & \\
Benzene & $7.80 \mathrm{E}+04$ & $1.78 \mathrm{E}+03$ & $2.30 \mathrm{E}-01$ & $7.94 \mathrm{E}+01$ & $8.77 \mathrm{E}+05$ & NA \\
Toluene & $9.20 \mathrm{E}+04$ & $5.20 \mathrm{E}+02$ & $2.70 \mathrm{E}-01$ & $2.51 \mathrm{E}+02$ & $8.67 \mathrm{E}+05$ & 0.114 \\
EC $>8-10$ & $1.20 \mathrm{E}+05$ & $6.50 \mathrm{E}+01$ & $4.90 \mathrm{E}-01$ & $1.58 \mathrm{E}+03$ & $8.71 \mathrm{E}+05$ & 0.057 \\
EC $>10-12$ & $1.30 \mathrm{E}+05$ & $2.50 \mathrm{E}+01$ & $1.40 \mathrm{E}-01$ & $2.51 \mathrm{E}+03$ & $9.04 \mathrm{E}+05$ & 0.057 \\
$\mathrm{EC}>12-16$ & $1.50 \mathrm{E}+05$ & $5.80 \mathrm{E}+00$ & $5.40 \mathrm{E}-02$ & $5.01 \mathrm{E}+03$ & $1.02 \mathrm{E}+06$ & 0.057 \\
EC $>16-21$ & $1.90 \mathrm{E}+05$ & $5.10 \mathrm{E}-01$ & $1.30 \mathrm{E}-02$ & $1.58 \mathrm{E}+04$ & $1.23 \mathrm{E}+06$ & NA \\
EC $>21-35$ & $2.40 \mathrm{E}+05$ & $6.60 \mathrm{E}-03$ & $6.80 \mathrm{E}-04$ & $1.26 \mathrm{E}+05$ & $1.28 \mathrm{E}+06$ & NA \\
\hline
\end{tabular}

\section{MODEL BASIS FOR FATE}

\section{AND TRANFORT OF TPH SOIL VAPOR}

Step 1: Estimation of soil gas concentrations with 3 or 4-phase soil partitioning equilibrium model at the source of contamination: When hydrocarbons are released into the subsurface, the model assumes that NAPL components will reach equilibrium with the four phases: air, water, soil, and residual NAPL. Assuming that there is no chemical or biological degradation or volatilization in the unsaturated source zone; equilibrium soil/water partitioning is instantaneous, reversible, and linear in the contaminated soil, a model could use a mass balance approach such that the total mass of each component $i$ in the system $\left(M_{T}{ }_{T}\right)$ is equal to the sum of the mass of each component $i$ in each of the four phases so that:

$$
M_{T}^{i}=M_{N A P L}^{i}+M_{w}^{i}+M_{a}^{i}+M_{s}^{i}
$$

where $M i$ stands for the mass of component $i$ in each of the four phases: NAPL, water, air, and soil (sorbed), which are represented by the subscripts $N A P L, w, a$, and $s$, respectively. The equations that govern the equilibrium partitioning between the phases are the linear sorption partitioning equation normalized with respect to organic carbon (Karichhoff and Brown, 1979), Henry's Law, and Raoult's Law, which can be written respectively as:

$$
\begin{aligned}
& C_{s, i}=K_{o c, i} f_{o c} C_{w, i} \\
& C_{a, i}=H_{i} C_{w, i} \\
& C_{w, i}=x_{i} S_{i}
\end{aligned}
$$

where $C_{i}$ is the concentration of component $i$ in each phase, $K_{o c, i}$ is the organic carbon water partitioning coefficient for each component, $f_{o c}$ is organic carbon fraction, $H_{i}$ is the dimensionless Henry's constant for each component $i$ at the temperature of interest, $x_{i}$ is the equilibrated mole fraction of the chemical component in the NAPL, $S_{i}$ is the aqueous solubility of the chemical component. The conservation of volume equation is written as:

$$
\theta_{w}+\theta_{a}+\theta_{N A P L}=n
$$

where $\theta_{w}$ is the volumetric water content, $\theta_{a}$ is the volumetric air content, $\theta_{N A P L}$ is the volumetric 
Table 2. Default Petroleum Product Weight Compositions

\begin{tabular}{lccccccc}
\hline & $\begin{array}{c}\text { Fresh } \\
\text { Gasoline }\end{array}$ & $\begin{array}{c}\text { Weathered } \\
\text { Gasoline }\end{array}$ & $\begin{array}{c}\text { JP-4 } \\
\text { Fuel }\end{array}$ & $\begin{array}{c}\text { Fresh } \\
\text { Diesel }\end{array}$ & $\begin{array}{c}\text { Weathered } \\
\text { Diesel }\end{array}$ & $\begin{array}{c}\text { Mineral } \\
\text { Oil }\end{array}$ & $\begin{array}{c}\text { Bunker } \\
\text { C }\end{array}$ \\
\hline Aliphatics & & & & & & & \\
EC $>5-6$ & 0.2600 & 0.0920 & 0.0070 & 0.0010 & 0.0001 & 0.0000 & 0.0000 \\
EC $>6-8$ & 0.1900 & 0.2750 & 0.2820 & 0.0030 & 0.0001 & 0.0000 & 0.0000 \\
EC $>8-10$ & 0.0900 & 0.1200 & 0.2560 & 0.0200 & 0.0110 & 0.0011 & 0.0000 \\
EC $>10-12$ & 0.0300 & 0.0130 & 0.1260 & 0.0800 & 0.0600 & 0.0028 & 0.0000 \\
EC $>12-16$ & 0.0000 & 0.0000 & 0.0940 & 0.2600 & 0.3000 & 0.1600 & 0.0950 \\
EC $>16-21$ & 0.0000 & 0.0000 & 0.0090 & 0.3400 & 0.3700 & 0.7000 & 0.1950 \\
Aromatics & & & & & & & \\
Benzene & 0.0250 & 0.0080 & 0.0002 & 0.0000 & 0.0000 & 0.0000 & 0.0000 \\
Toluene & 0.1200 & 0.0980 & 0.0080 & 0.0000 & 0.0000 & 0.0000 & 0.0000 \\
EC $>8-10$ & 0.2600 & 0.3800 & 0.0160 & 0.0050 & 0.0006 & 0.0013 & 0.0000 \\
EC $>10-12$ & 0.0250 & 0.0140 & 0.0530 & 0.0230 & 0.0062 & 0.0014 & 0.0000 \\
EC $>12-16$ & 0.0000 & 0.0000 & 0.1010 & 0.0660 & 0.0320 & 0.0074 & 0.1450 \\
EC $>16-21$ & 0.0000 & 0.0000 & 0.0188 & 0.1800 & 0.1880 & 0.0800 & 0.3610 \\
EC $>21-35$ & 0.0000 & 0.0000 & 0.0290 & 0.0220 & 0.0320 & 0.0460 & 0.2040 \\
\hline
\end{tabular}

NAPL content, and $n$ is the porosity. The porosity and the volumetric water content are assumed to have fixed values. The mass of each component at each phase is determined with equations 2,3 , and 4 as follows:

$$
\begin{aligned}
& M_{T}^{i}=C_{T, i} \rho_{b} V \\
& M_{s}^{i}=C_{s, i} m_{s o i l}=C_{s, i} r_{b} V= \\
& =K_{o c, i} f_{o c} C_{w, i} r_{b} V \\
& M_{w}^{i}=C_{w, i} \theta_{w} V \\
& M_{a}^{i}=C_{a, i} \theta_{a} V=H_{i} C_{w, i} \theta_{a} V
\end{aligned}
$$

where $C_{T}$ is the total soil concentration, $\rho_{b}$ is the dry soil bulk density, $V$ is the total soil sample volume, $m_{\text {soil }}$ is the total mass of the soil. Assuming that NAPL phase is not present at the source, then a 3-phase model should be able to handle the distribution of each component as described below. Substituting equations $6,7,8$ and 9 into equation 1, assuming $M^{i}{ }_{N A P L}$ is equal to zero (no NAPL phase), and rearranging with respect to soil vapor concentration $\left(C_{a, i}\right)$ and total soil concentration of component i $\left(C_{T, i}\right)$ :

$$
C_{a, i}=\frac{C_{T, i} H_{i} \rho_{b}}{\theta_{w}+K_{o c, i} f_{o c} \rho_{b}+H_{i} \theta_{a}}
$$

where a NAPL phase exists, as described by Roberts and Allen-King (1998), substitution of equations 5 through 9 into equation 1 and rearranging terms, the resulting equation takes the form:

$$
\begin{aligned}
& C_{T, i}=\frac{M_{T}^{i}}{m_{\text {soil }}}=\frac{x_{i} S_{i}}{\rho_{b}} \\
& {\left[\theta_{w}+K_{o c, i} f_{o c} \rho_{b}+H_{i} \theta_{a}+\frac{M W_{i}}{S_{i}} \rho_{N A P L} \theta_{N A P L}\right]}
\end{aligned}
$$

where $M W_{i}$ is the molecular weight of pure NAPL component $i$, and $\rho_{N A P L}$ is the molar density of the NAPL. Assuming that the NAPL is an ideal mixture, $\rho_{N A P L}$ is estimated as a weighted average of the components by calculating the density of the NAPL mixture and then dividing by the molecular weight of the NAPL mixture such that:

$\rho_{N A P L}=\frac{\left[\frac{\sum\left(x_{i} M W_{i}\right)}{\sum\left(x_{i} M W_{i} / \rho_{i}\right)}\right]}{\sum\left(x_{i} M W_{i}\right)}=\frac{1}{\sum\left(x_{i} M W_{i} / \rho_{i}\right)}$ 
where $\rho_{i}$ is the density of each NAPL component. Equation 11 is written for each component so that the resulting system of mass balance equations contains 13 equations (one for each EC group), each with two unknowns: $x_{i}$, which is different for each EC group, and $\theta_{N A P L}$, which is common to all of the equations. A unique set of solutions for $x_{i}$ is obtained by solving a series of mass balance equations simultaneously using the iterative spreadsheet routine built in MS EXCELTM Solver - with the restrictions that the volume is conserved and the sum of the mole fractions is equal to one:

$$
\sum x_{i}=1
$$

when a NAPL phase is present, all equations are satisfied; the volumetric oil content $\left(\theta_{N A P L}\right)$ is always positive. Once $x_{i}$ is computed with the iteration technique, the soil vapor concentration $\left(C_{a, i}\right)$ at source could be easily estimated with equations 3 and 4 . As Figure 1 illustrates, soil vapor concentration is proportional to the residual level in the soil in the limit of "low" residual levels (3-phase) where compounds are sorbed to the soil, dissolved in the soil moisture, and present in the soil vapor space; soil vapor concentration is independent of the residual level, but a function of composition for "high" residual levels (4-phase) where free-phase liquid or precipitate is trapped in the soil interstices. When NAPL phase is being detected (mathematically positive term) using 4-phase partitioning model, a solution computed by a 4-phase model is chosen as a true value, otherwise a solution by a 3-phase model is

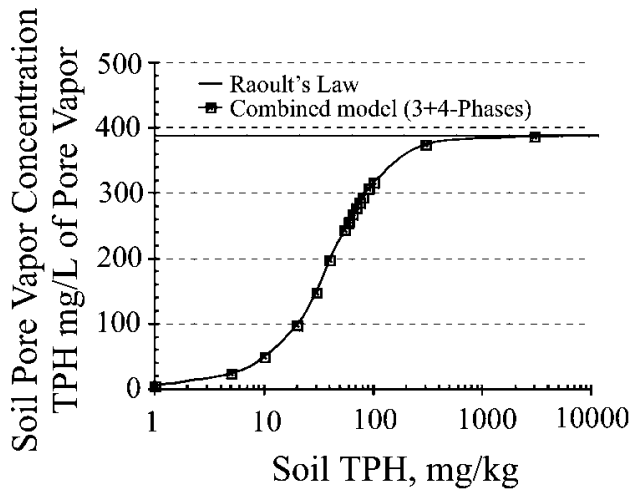

chosen. As shown in Figure 2, the mass distribution patterns between total soil concentration and soil vapor phase are not identical.

In the fresh gasoline contaminated soil, a dominant portion $(80 \%)$ of hydrocarbons in soil vapor phase is found to be Aliphatic EC >5-6.

\section{Step 2: Estimation of emissions by convection and} diffusion mechanisms: As multi-phase equilibrium partitioning in the subsurface unsaturated zone provides soil pore vapor concentration of each TPH fraction, soil-gas entry into buildings is the result of both diffusive and convective transport processes. The model incorporates both convective and diffusive mechanisms for both steady-state and quasisteady-state solutions, as well as building foundation properties. A heuristic model (Johnson and Ettinger, 1991) is selected and slightly modified for the calculation of the attenuation coefficient due to diffusive and convective transport in the model development. The model incorporates a number of key assumptions, including no leaching of contaminant to groundwater, no sinks in the building, and well-mixed air volume within the building.

Consider a contaminant vapor source located some distance $\left(L_{T}\right)$ below the floor of an enclosed building constructed with a basement or constructed slab-on-grade. At the top boundary of contamination, molecular diffusion moves the volatilized contaminant towards the soil surface until it reaches the zone of influence of the building. Here convective air movement within the soil column transports the vapors through cracks between the foundation and the basement slab floor. This convective sweep effect is induced by a negative pressure within the structure. Under the

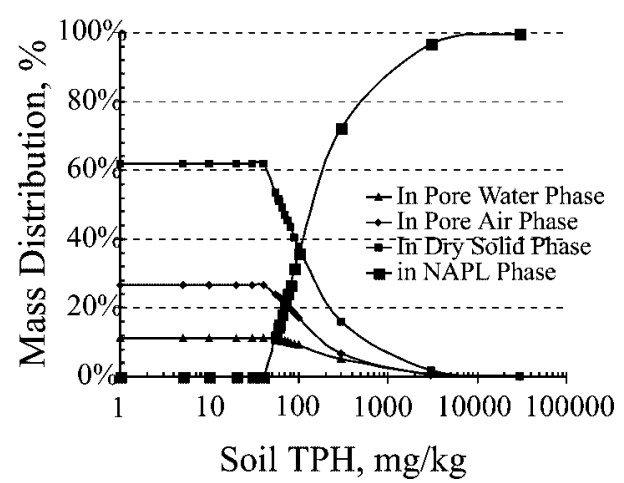

Figure 1. Soil Vapor Concentration and Mass Distribution Predicted by the Combination of 3 and 4-Phase Partitioning Models at Fresh Gasoline, $\mathrm{f}_{\mathrm{oc}}=0.1 \%$ 


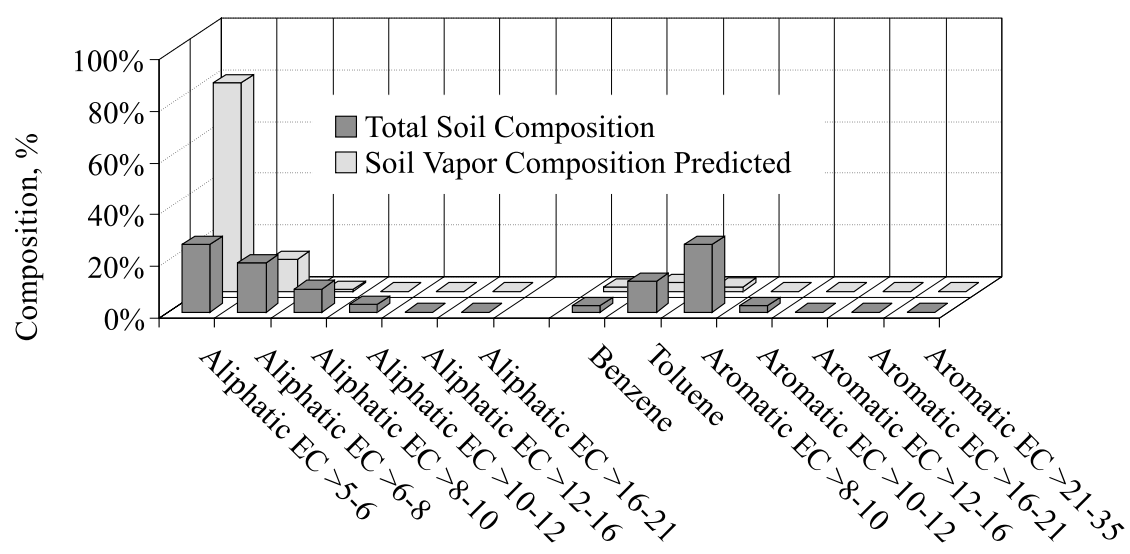

Figure 2. Relative Distribution of Equivalent Carbon in Different Media at Fresh Gasoline Soil TPH $300 \mathrm{mg} / \mathrm{kg}, \mathrm{f}_{\mathrm{oc}}=0.1 \%$

assumption that mass transfer is steady-state (infinite source), the model gives the solution for the attenuation coefficient, $\alpha$, whereas, the thickness of soil contamination is known, the finite source solution of model can be employed such that the time-averaged attenuation coefficient, $\langle\alpha\rangle$, may be calculated, respectively, as:

$$
H_{T^{o} K}=H_{20^{\circ} C}\left(10^{-B\left(\frac{1}{T^{o} K}-\frac{1}{293}\right)}\right)
$$

where " $B$ " for hydrocarbons was found to be "1,700". Soil vapor permeability, $k_{v}$, was estimat-

$$
a=\frac{\left[\left(\frac{D_{T}^{\text {eff }} A_{B}}{Q_{\text {building }} L_{T}}\right) x \exp \left(\frac{Q_{\text {soil }} L_{\text {crack }}}{D^{\text {crack }} A_{\text {crack }}}\right)\right]}{\left[\exp \left(\frac{Q_{\text {soil }} L_{\text {crack }}}{D^{\text {crack }} A_{\text {crack }}}\right)+\left(\frac{D_{T}^{\text {eff }} A_{B}}{Q_{\text {building }} L_{T}}\right)+\left(\frac{D_{T}^{\text {eff }} A_{B}}{Q_{\text {soil }} L_{T}}\right)\left[\exp \left(\frac{Q_{\text {soil }} L_{\text {crack }}}{D^{\text {crack }} A_{\text {crack }}}\right)-1\right]\right]}
$$

$$
\langle a\rangle=\frac{\rho_{b} C_{T, i} \Delta H_{c} A_{B}}{Q_{b u i l d i n g} C_{a, i} \tau}\left(\frac{L_{T}^{0}}{\Delta H_{c}}\right)\left[\left(\beta^{2}+2 \Psi \tau\right)^{1 / 2}-\beta\right]
$$

Refer to the original paper (Johnson and Ettinger, 1991) and Table 3 for more detailed calculations and input parameters.

Step3: Determination of significant variables and calculation of HI of TPH at indoor air: The temperature adjustment factor was included in equilibrium partitioning and diffusion coefficient calculations to account for reduced volatility of the contaminant in soil. Henry's law constant $(H)$ of $\mathrm{EC}$ at the average soil temperature may be estimated using the simplified form of the vant's Hoff equation and experimental correlation done by Staudinger et al. (1996) as: ed by the mean saturated hydraulic conductivity (Carsel and Parrish, 1988; Crum and Przybysz, 1998). Fine sand was selected as a default soil type for calculation of $k_{v}$ value: i.e., $1 \times 10^{-8} \mathrm{~cm}^{2}$.

Regional data were used to establish default values for residential building size and type with the literature (Crum and Przybysz, 1998) as shown in Table 3. Calculation of a HI (Hazard Index) of the non-carcinogenic air TPH contaminant should take the form with the adjustment for additive risk of TPH as described by WDOE (1997):

$$
H I=\frac{(B R)^{*}(A B S)}{(A B W)^{*}(U C F)} \sum_{i} \frac{C_{\text {building }, i}}{R f C_{i}}
$$

where $B R$ is the Breathing Rate $\left(10 \mathrm{~m}^{3} / \mathrm{d}\right), A B S$ is the Inhalation Absorption Rate (1.0), $A B W$ is the 
Table 3. Default Values of Model Input Parameters

\begin{tabular}{lccc}
\hline \multicolumn{1}{c}{ Parameter } & Symbol & Units & Value \\
\hline Soil Parameters & & & \\
Dry soil bulk density & $\rho_{b}$ & $\mathrm{~g} / \mathrm{cm}^{3}$ & $1.85 \mathrm{E}+00$ \\
Total soil porosity & $n$ & dimensionless & $4.21 \mathrm{E}-01$ \\
Volumetric water content in vadose zone & $\theta_{w}$ & dimensionless & $3.21 \mathrm{E}-01$ \\
Air-filled soil porosity & $\theta_{a}$ & dimensionless & $1.00 \mathrm{E}-01$ \\
Fraction organic carbon & $f_{o c}$ & dimensionless & $1.00 \mathrm{E}-03$ \\
Ground temperature, ${ }^{\circ} \mathrm{K}=273+12^{\circ} \mathrm{C}$ & & ${ }^{\circ}$ & $2.85 \mathrm{E}+02$ \\
Soil Air Permeability (fine sand) & $k_{v}$ & $\mathrm{~cm}^{2}$ & $1.00 \mathrm{E}-08$ \\
Building Envelope & & & \\
Area of cracks/total area: $\mathrm{A}_{\text {crack }} / \mathrm{A}_{\mathrm{B}}$, or Crack Ratio & $\eta$ & dimensionless & $1.00 \mathrm{E}-03$ \\
Indoor-outdoor pressure difference & $\Delta \mathrm{P}$ & $\mathrm{g} / \mathrm{cm}^{2} / \mathrm{s}^{2}$ & $1.00 \mathrm{E}+01$ \\
Building square footage & $\mathrm{A}_{\mathrm{B}}$ & $\mathrm{cm}$ & $1.96 \mathrm{E}+06$ \\
Building ventilation rate & $\mathrm{Q}_{\text {building }}$ & $\mathrm{cm} / / \mathrm{s}$ & $2.04 \mathrm{E}+05$ \\
Area of cracks through which vapors can enter & $\mathrm{A}_{\text {crack }}$ & $\mathrm{cm}$ & $1.96 \mathrm{E}+03$ \\
Total length of cracks & $\mathrm{X}_{\text {crack }}$ & $\mathrm{cm}$ & $5.60 \mathrm{E}+03$ \\
Equivalent radius (crack width) & $\mathrm{r}_{\text {crack }}$ & $\mathrm{cm}$ & $3.50 \mathrm{E}-01$ \\
Building ceiling height & $\mathrm{H}_{\mathrm{B}}$ & $\mathrm{cm}$ & $2.50 \mathrm{E}+02$ \\
Ventilation exchange rate & $\mathrm{ER}^{2}$ & $\mathrm{hr}-1$ & $1.50 \mathrm{E}+00$ \\
Thickness of foundation & $\mathrm{L}_{\text {crack }}$ & $\mathrm{cm}$ & $1.50 \mathrm{E}+01$ \\
Depth of foundation (or basement) below ground & $\mathrm{Z}_{\text {crack }}$ & $\mathrm{cm}$ & $1.50 \mathrm{E}+01$ \\
Distance from contaminant source to foundation & $\mathrm{L}_{\mathrm{T}}$ & $\mathrm{cm}$ & $1.50 \mathrm{E}+01$ \\
Initial contaminant-building floor separation & $\mathrm{L}_{\mathrm{T}}$ & $\mathrm{cm}$ & $1.50 \mathrm{E}+01$ \\
Thickness of contaminant interval & $\Delta \mathrm{H}_{\mathrm{C}}$ & $\mathrm{cm}$ & $2.00 \mathrm{E}+02$ \\
\hline
\end{tabular}

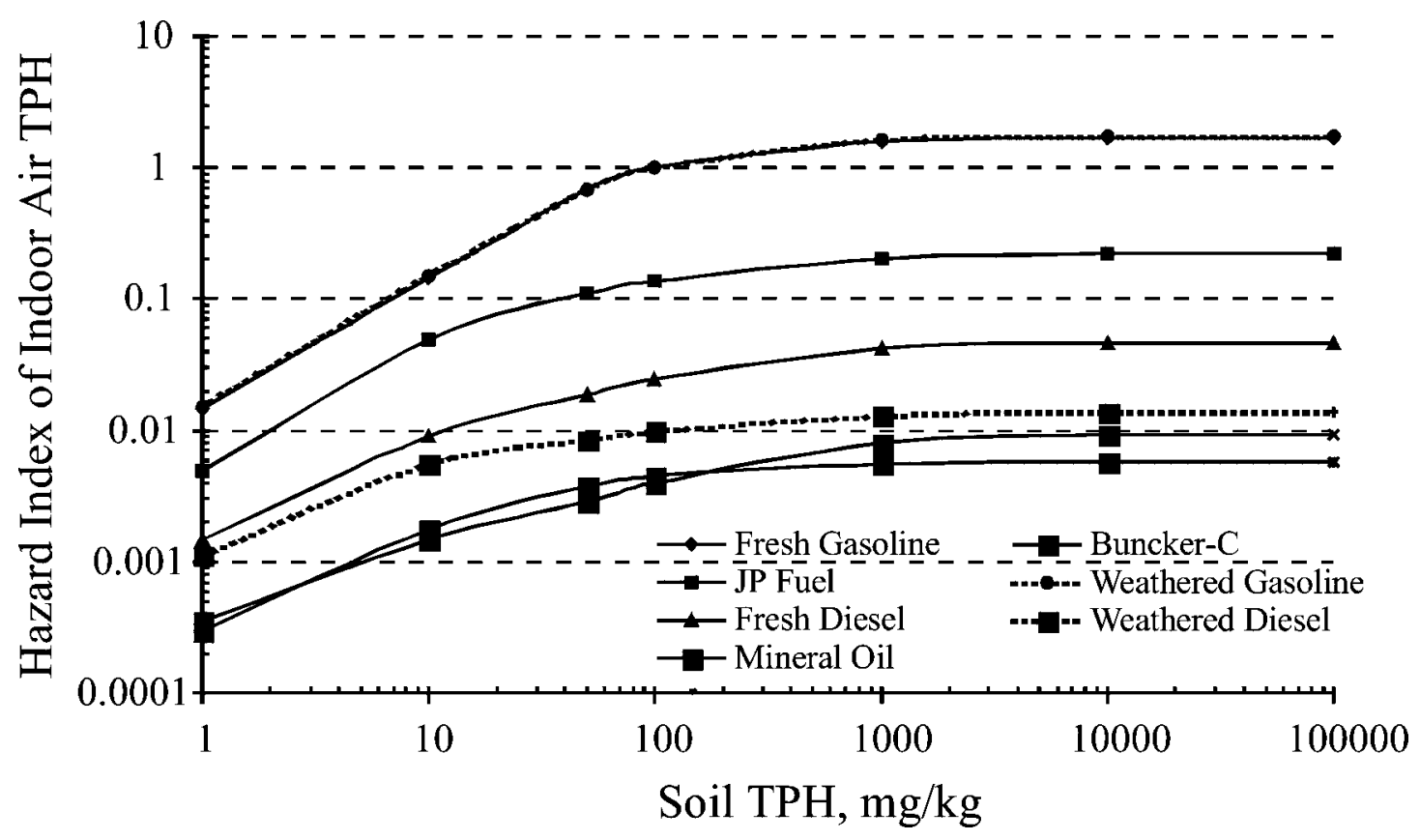

Figure 3. Dependence of Hazard Index on Soil TPH of Different Fuel Type at $\mathrm{f}_{\mathrm{oc}}=0.1 \%, \mathrm{k}_{\mathrm{v}}=10^{-8} \mathrm{~cm}^{2}, \mathrm{LT}=100 \mathrm{~cm}$, Crack Ratio $=0.1 \%$; Infinite Source 
Average Body Weight (16 kg), UCF is the Units Conversion Factor $(1,000 \mathrm{ug} / \mathrm{mg}), C_{\text {building }}$ is the indoor air concentration $\left(\mathrm{ug} / \mathrm{m}^{3}\right)$.

\section{SENSITIVITY ANALYSIS AND APPLICATION OF MODEL}

Previous study indicated that the most sensitive parameters affecting long-term building concentration are soil organic carbon content $\left(f_{o c}\right)$, distance from the source $\left(L_{T}\right)$, soil permeability to vapor flow $\left(k_{v}\right)$, and crack ratio $(\eta)$. HI of indoor air TPH was calculated as a function of different fuel type under the identical default site condition as shown in Figure 3.

For practical purposes, it can be concluded that as far as a certain distance $(100 \mathrm{~cm})$ between the source and building foundation exists, the gasoline contaminated soil vapor only could be a significant source for indoor air TPH contaminant. Figure 4 presents the predicted $\mathrm{HI}$ values of indoor air TPH for $\eta=1 \%$ and $0.1 \%$, as a function of soil vapor permeability, for $\mathrm{L}_{\mathrm{T}}=15 \mathrm{~cm}$, and $500 \mathrm{~cm}$ along the different source type and $f_{o c}$. In each figure the dependence of HI on $k_{v}$ is a sigmoid-shaped curve. Figure 4 illustrates the strong dependence of $\mathrm{HI}$ on soil type in general. The model predicts that $\mathrm{HI}$ is independent of $k_{v}$ for "small" values of $k_{v}$ and becomes proportional to $k_{v}$ at "mid" ranges values of $k_{v}$, and becomes independent of $k_{v}$ for "large" values of $k_{v}$ again.
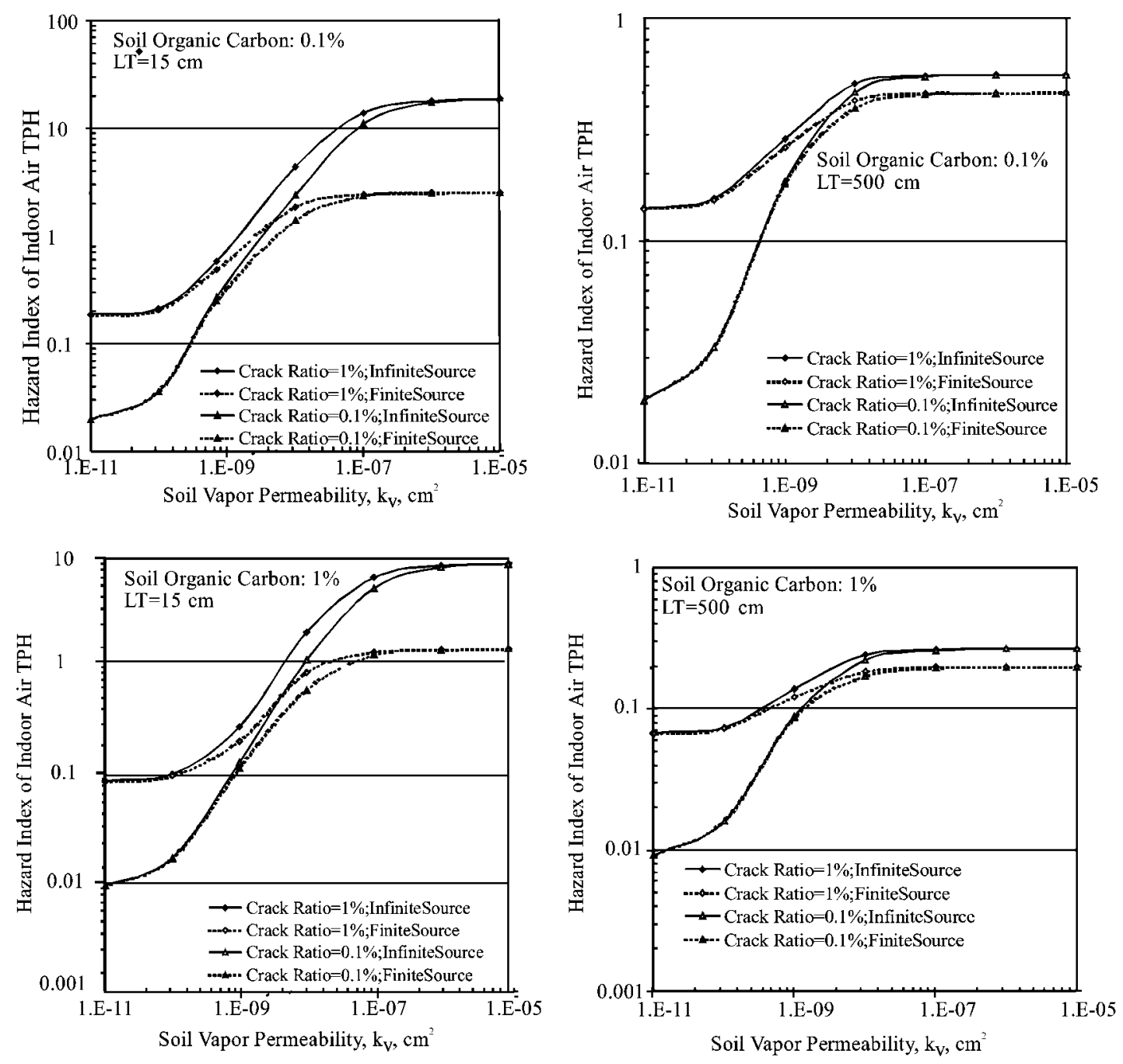

Figure 4. Dependence of Hazard Index on Soil Vapor Permeability as Predicted by the Model at Fresh Gasoline Default Composition, Soil TPH $=300 \mathrm{mg} / \mathrm{kg}$ 

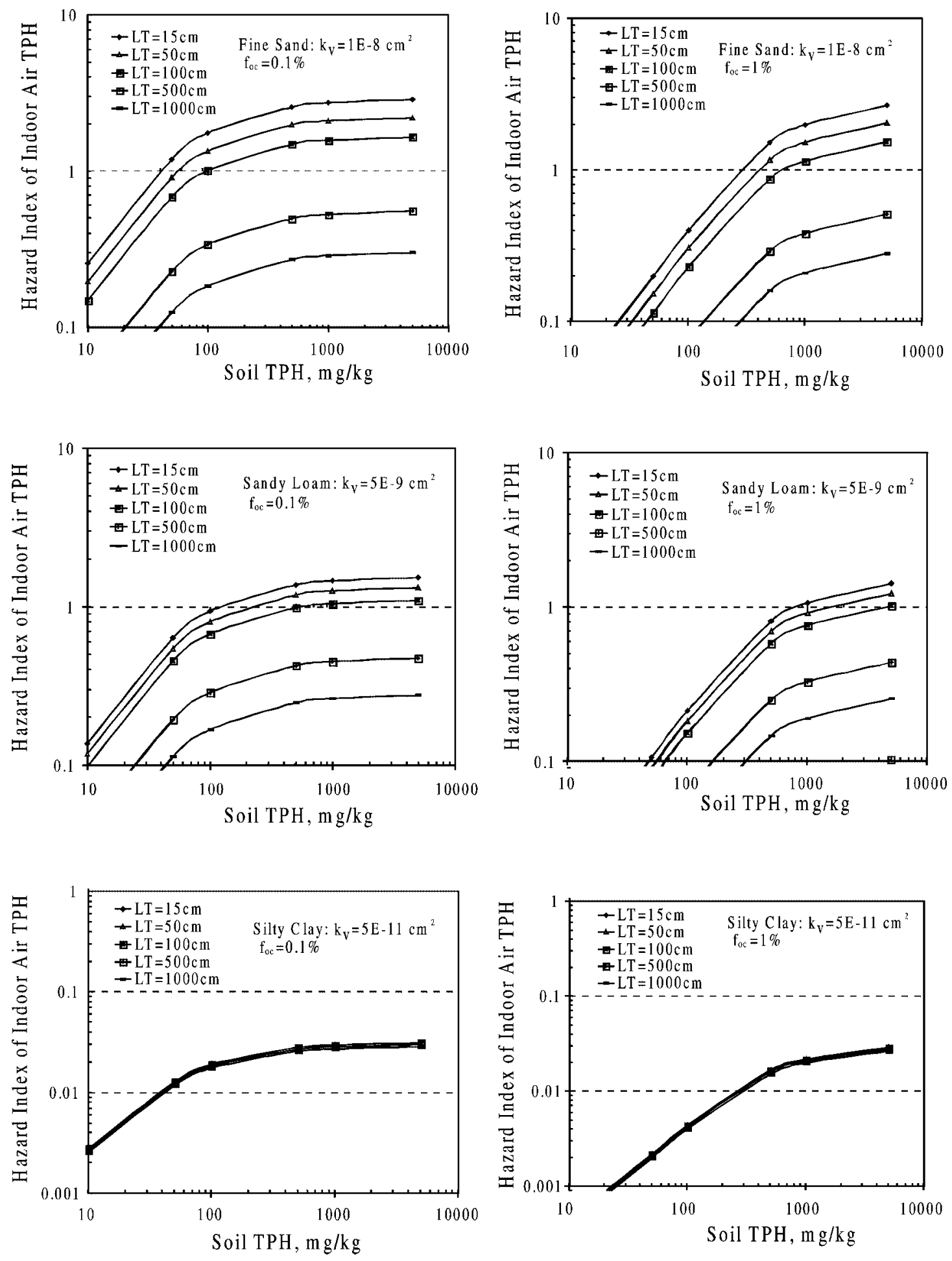

Figure 5. Variation of Hazard Index with the Distance from Contaminant Source at Fresh Gasoline Default Composition; Infinite Source 
Table 4. Sample Calculation of Indoor Air Hazard Index

\begin{tabular}{|c|c|c|c|c|}
\hline$f_{o c}, \%$ & $k_{v}, \mathrm{~cm}^{2}$ & HI (see figure 5.) & HI at $k_{v}=7 \mathrm{E}-10 \mathrm{~cm}^{2}$ & $\mathrm{HI}$ at $\mathrm{f}_{\mathrm{oc}}=0.7 \%$, \\
\hline \multirow{3}{*}{$0.1 \%$} & & & & $k_{v}=7 \mathrm{E}-10 \mathrm{~cm}^{2}$ \\
\hline & $5.00 \mathrm{E}-09$ & $9.90 \mathrm{E}-01$ & & \multirow{4}{*}{ 1.12E-01 } \\
\hline & 5.00E-11 & 2.79E-02 & 1.54E-01 & \\
\hline \multirow[t]{2}{*}{$1.0 \%$} & $5.00 \mathrm{E}-09$ & $5.82 \mathrm{E}-01$ & & \\
\hline & $5.00 \mathrm{E}-11$ & $1.64 \mathrm{E}-02$ & 9.07E-02 & \\
\hline
\end{tabular}

Note: All HI values are when soil fresh gasoline TPH is $500 \mathrm{mg} / \mathrm{kg}$ and $L_{T}=100 \mathrm{~cm}$

Table 5. Comparison of Soil TPH Gas Monitoring Data with the Predicted

\begin{tabular}{l|l|ccc}
\hline \multicolumn{2}{l|}{} & Benzene & Toluene & m\&p-Xylene \\
\hline \multicolumn{2}{l}{$\begin{array}{l}\text { Measured Source Soil Concentration } \\
\text { at source at } 1.5 \mathrm{~m} \text { BGS, mg/kg }\end{array}$} & 1160 & 9500 & 930 \\
\hline \multirow{2}{*}{$\begin{array}{l}\text { Soil Vapor Concentration } \\
\text { at Source, } \mathrm{mg} / \mathrm{L}\end{array}$} & Measured: & $15 \sim 23$ & $\mathrm{NA}$ & $\mathrm{NA}$ \\
\cline { 2 - 5 } & Predicted: & 29 & 72 & 2.2 \\
\hline $\begin{array}{l}\text { Indoor Air Concentration } \\
\mu \mathrm{g} / \mathrm{m}^{3}\end{array}$ & Measured: & $2.3 \sim 18$ & $16 \sim 61$ & $4.6 \sim 8.0$ \\
\cline { 2 - 5 } & Predicted: & 2640 & 6520 & 203 \\
\hline
\end{tabular}

The transition between these three regimes occurs near $k_{v}=10^{-10}$ and $10^{-8} \mathrm{~cm}^{2}$. Clearly, predictions are insensitive to $\eta$ and sensitive to the assumption of source type in the limit of "permeable" soils and a large source-foundation separation $\left(L_{T}\right)$. The relationship between subsurface gasoline TPH concentration and its corresponding indoor air quality $\mathrm{HI}$ is illustrated in Figure 5 as a function of important parameters such as soil-vapor permeability, soil-organic carbon content, and contaminant source distance. Assuming a proportionality between all adjacent data points in Figure 5, it could be used for the illustration of site specific soil vapor-to-indoor air exposure risk calculation with the limited data given as follows: Estimate HI of indoor air quality due to the fresh gasoline contaminated soil (@ TPH $500 \mathrm{mg} / \mathrm{kg}$ ) located below $100 \mathrm{~cm}$ from the building foundation with $f_{o c}=0.7 \%$ and silty loam soil $\left(k_{v}=7 \times 10^{-10} \mathrm{~cm}^{2}\right)$. The value of HI should be "0.11" as illustrated in Table 4. Model predictions are compared to the experimental case histories to assess if any agreement exists. The field site is the former Chatterton petroleum plant located near Delta, BC, Canada. Soil contamination included mainly benzene, toluene, and $m \& p$-xylene distributed in laterally extensive smear zone of residual NAPL. Hers and Zap-Gilj (1998) monitored the hydrocarbon fate and transport in the vadose zone, and intrusion over one-year period. The measured soil vapor concentrations at the source zone are close to those predicted by the study model assuming equilibrium partitioning as indicated in Table 5 . However, the model predicted that hydrocarbon intrusion in the indoor air is almost two orders of magnitude greater than that measured. In addition, significant bioattenuation of hydrocarbons in soil vapor was observed over a small depth interval below and adjacent to the building.

\section{CONCLUSIONS}

An attempt is made to predict the intrusion rate of hydrocarbon contaminant vapors into buildings through foundations in a general scenario. Hazard Index of indoor air migrated from petroleum-contaminated subsurface soil is computed as a function of several important parameters under the default site conditions. For the reliable estimation of $\mathrm{HI}$ of indoor air arising from the migration of petroleum-contaminated soil vapors, a critical procedure is to predict indoor air concentration (with acceptable accuracy). The limited soil TPH monitoring data and the predicted values computed by three important mechanisms of equilibrium partitioning and subsequent diffusive and convective transport are quite far to be comparable. 
Thus, a better understanding of soil vapor migration to enclosed space and its field validation are needed. This approach slould be used as a risk-assessment screening-level tool; it can be used to identify sites, or contaminant levels, for which contaminant exposures through a vapor inhalation pathway may cause adverse health effects.

\section{REFERENCES}

Carsel, R.F., Parrish, R.S. (1988), Developing joint probability distributions of soil water retention characteristics, Water Resources Research, 24, 755-769.

Crum, J., Przybysz, R. (1998), Michigan's approach for evaluating vapor migration of contamination from groundwater and soil to indoor air at UST release sites, Proceedings of the 1998 Petroleum Hydrocarbons and Organic Chemicals in Groundwater: National Groundwater Water Association, Houston Texas, pp. 230-250.

Gustafson, J.B., Tell, J.G., and Orem, D. (1997), Selection of representative TPH fractions based on fate and transport considerations, TPH National Criteria Working Group, Vol. 3, Amherst Scientific Publisher.

Hers, I., Zapf-Gilj, R. (1998), Canadian Consortium Research Project - field validation of soil gas transport to indoor air pathway, Proceedings of the 1998 Petroleum Hydrocarbons and Organic Chemicals in Groundwater: National Groundwater Water Association, Houston Texas, pp. 251-266.

Johnson, P.C., Ettinger, R.A. (1991), Heuristic model for predicting the intrusion rate of contaminant vapors into buildings, Environ. Sci. Technology, 25, 1445-1452.

Karichhoff, S.W., Brown, D.S. (1979), Sorption of hydrophobic pollutants on natural sediments, Water Research, 13, 241-248.

Roberts, L. M., Allen-King, R. M. (1998), Testing the chemical assumptions in the TPH interim policy for protectiveness, Final Report for Department of Ecology, Washington State.

Staudinger, J., Robers, P. (1996), A critical review of Henry's law constants for environmental applications, Critical Reviews in Environmental Sci. and Tech., 26, 205-297.

WDOE (1997), Interim interpretive and policy statement: Cleanup of total petroleum hydrocarbons, Washington Department of Ecology, ECY97-600. 